\title{
Congenital duodenal obstruction with delayed presentation: seven years of experience
}

Seyed Abdollah Mousavi ${ }^{1}$, Hasan Karami ${ }^{2}$, Hossein Saneian ${ }^{3}$

${ }^{1}$ Department of Pediatric Surgery, Faculty of Medicine, Mazandaran University of Medical Sciences, Sari, Iran

${ }^{2}$ Department of Pediatric Gastroenterology, Faculty of Medicine, Mazandaran University of Medical Sciences, Sari, Iran

${ }^{3}$ Department of Pediatric Gastroenterology, Faculty of Medicine, Isfahan University

of Medical Sciences, Isfahan, Iran

Submitted: 4 October 2014

Accepted: 22 November 2014

Arch Med Sci 2016; 12, 5: 1023-1027

DOI: $10.5114 /$ aoms.2016.60045

Copyright @ 2016 Termedia \& Banach

\section{Abstract}

Introduction: The duodenum is the most common site for congenital intestinal obstruction. The duodenal web with a central hole can present without any overt signs of obstruction at a later age.

Material and methods: Over a 7-year period, children with congenital intestinal obstruction were identified in this study. The complications and operative findings of patients with duodenal web with conditions such as wind sock deformity and delayed diagnosis were evaluated in this study.

Results: This study included 81 infants with congenital intestinal obstruction. At operation, 48 patients demonstrated duodenal obstruction with atresia in 27, annular pancreas in 15 and malrotation in 6 . Also, we observed incomplete obstruction of the duodenum due to a fenestrated web in 8 patients. The age of these patients at operation time ranged from 5 days to 72 months. Fifty percent of affected patients were associated with trisomy 21 , all of whom exhibited failure to thrive due to food intolerance. The patients older than 2 years presented with major complications of gastroesophageal reflux such as esophageal ulcer, stricture and dysphagia. Additionally we had a unique case of a patient who had been referred with an epigastric mass. During the operation, we found 440 seeds of various fruits in the stomach and the first portion of the duodenum.

Conclusions: Our study emphasizes that duodenal web with a central hole can present without signs of obstruction at a later age with only failure to thrive and food intolerance. Therefore a high index of suspicion is necessary for diagnosis when it presents beyond the usual age.

Key words: duodenum, obstruction, web.

\section{Introduction}

The duodenum is the most common site of intestinal obstruction, accounting for nearly half of all cases, while the ileum is the least affected $[1,2]$. The incidence of duodenal atresia and stenosis ranges from 1 in 4,000 to 1 in 15,000 live births [3]. On the other hand, duodenal diaphragm is an uncommon disease and occurs in 1 per 20,000 to 40,000 live births [4, 5], affecting boys more commonly than girls, although in some studies the sex distribution is about even between males and females [6].

\author{
Corresponding author: \\ Seyed Abdollah Mousavi \\ Department of Pediatric \\ Surgery \\ Faculty of Medicine \\ Mazandaran University \\ of Medical Sciences \\ Start of Valiye Asr Highway \\ Joybar 3Way, Imam Sq. \\ 4817844718 Sari \\ Mazandaran, Iran \\ Phone: +98 1133257230 \\ E-mail: s_kavardi@yahoo. \\ com.sg
}


Duodenal stenosis is observed in $75 \%$ of cases in the third to fourth section of the duodenum [4]. Also, most of the webs occur proximal to or near the ampulla of Vater, with $10 \%$ being found proximal to the ligament of Treitz [7].

Congenital duodenal web with a central hole can present without signs of obstruction at a later age. Therefore a high index of suspicion is necessary to diagnose when they present beyond the usual age $[4,8,9]$. Due to the importance of early diagnosis, a retrospective review of patients with congenital duodenal obstruction was performed to identify late presentation of duodenal web.

\section{Material and methods}

Over a 7-year period (2006 to 2013) children with congenital intestinal obstruction were identified at the Booali Sina Hospital, Sari, Iran. Patients with the diagnosis of duodenal obstruction were selected for the occurrence of early or late signs and symptoms of presentation by a retrospective analysis. Patients with duodenal web with wind sock deformity and delayed diagnosis were evaluated. After a barium meal, esophagogastroduodenoscopy was performed for older and complicated patients. An assessment of the complications of delayed management was conducted and key points of early diagnoses were reviewed. The Research Ethics Committee of the Hospital approved this research project and family consent was taken.

\section{Results}

This study included 81 infants with congenital intestinal obstruction. There were 37 girls and 44 boys. At operation, 48 (58.2\%) patients were found with duodenal obstruction, atresia in 27 (56.2\%), annular pancreas in 15 (31.25\%) and malrotation in $6(12.5 \%)$. Also, the location of atresia in 24 (29.6\%) and 9 (11.1\%) subjects was subsequently in the jejunum and ileum (Figure 1). One case with ileocecal valve atresia was classified in the ileal group [10]. On the other hand, 12 (14.8\%) patients were premature and 8 (9.8\%) had Down's syndrome. In cases with trisomy 21 the location of obstruction was in the duodenum (atresia in 7 and annular pancreas in 1 patient).

An incomplete obstruction of the duodenum was identified due to a fenestrated web or diaphragm in 8 patients. The presentation of patients older than neonatal age was in early or beyond infancy with food intolerance and failure to thrive (FTT) (Table I).

The age of patients at operation time ranged from 5 days to 72 months (mean: 26.7 months). In the past medical history the signs and symptoms of partial intestinal obstruction had started in early infancy. Patients older than 2 years presented with major complications of gastroesophageal reflux such as gastroduodenitis, esophagitis, esophageal ulcer and stricture and FTT. We had the opportunity of being presented with a rare case of an individual who had referred to our center for management of FTT (case 4). Due to weekly non-bilious vomiting and an epigastric mass in palpation, we had taken a plain abdomen X-ray and barium meal. "Soap bubble" appearance in combination with atypical "double bubble" suggested duodenal web associated with numerous foreign bodies. During the operation, we found 440 (190 g) seeds of peach, apricot, date and palm kernel and nuts of varying sizes and a small piece of a plastic that impacted the small aperture of the diaphragm, which allowed only a $12 \mathrm{Fr}$ feeding tube to pass through (Figures 2 and 3).

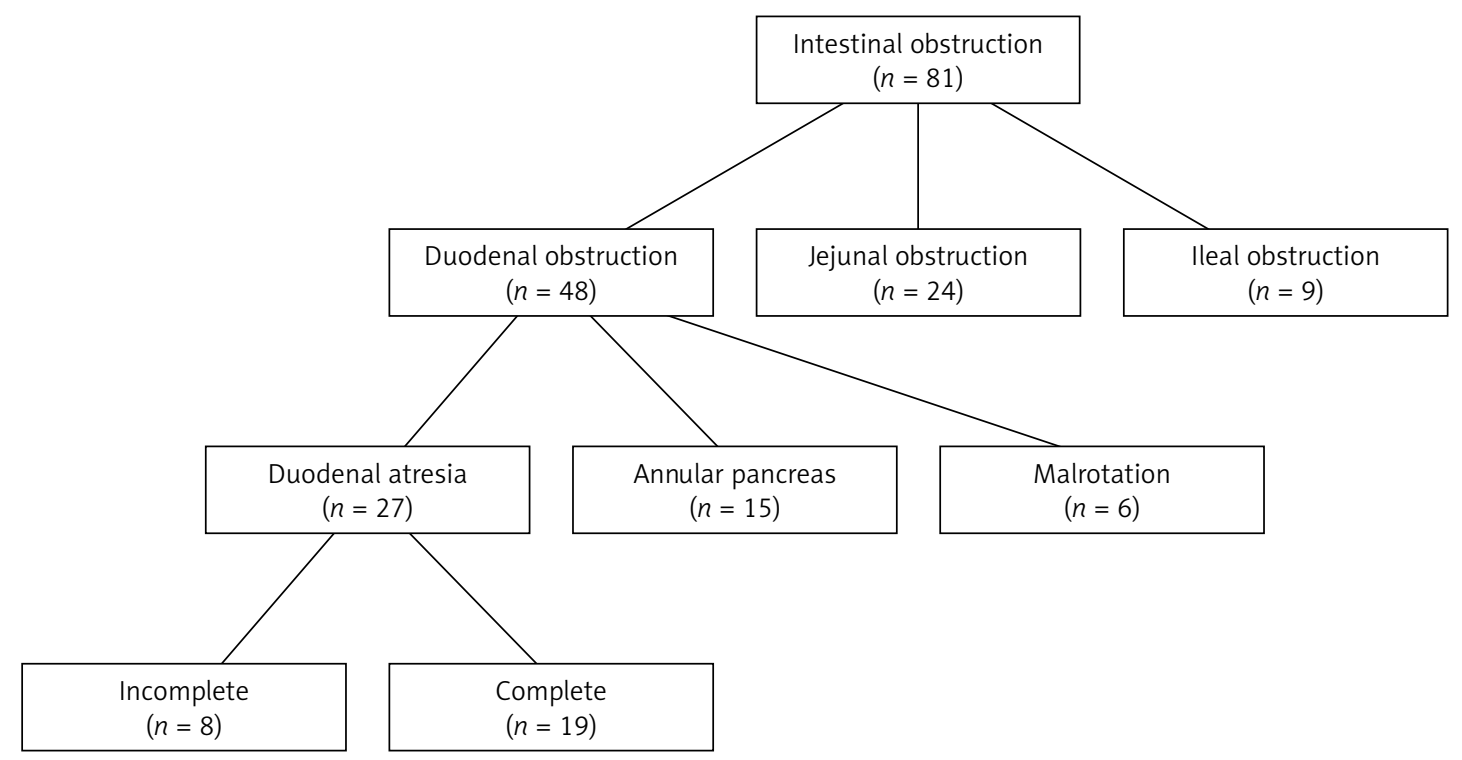

Figure 1. Distribution of congenital small intestinal obstruction in 81 children 
Table I. Characteristics of patients with duodenal web and delayed presentations

\begin{tabular}{|c|c|c|c|c|c|c|c|}
\hline Patient & $\begin{array}{c}\text { Age } \\
\text { [months] }\end{array}$ & Gender & $\begin{array}{l}\text { Weight } \\
\text { [kg] }\end{array}$ & $\begin{array}{l}\text { Associated } \\
\text { anomaly }\end{array}$ & $\begin{array}{l}\text { Signs and } \\
\text { symptoms }\end{array}$ & Barium meal & $\begin{array}{l}\text { Endoscopic } \\
\text { findings }\end{array}$ \\
\hline 1 & 20 & $M$ & 8.2 & $\begin{array}{l}\text { Single kidney, } \\
\text { trisomy } 21\end{array}$ & $\begin{array}{c}\text { Vomiting, } \\
\text { hematemesis, } \\
\text { GER }\end{array}$ & GD & $\begin{array}{c}\text { Esophago- } \\
\text { gastroduodenal } \\
\text { ulcers }\end{array}$ \\
\hline 2 & 10 & $\mathrm{~F}$ & 7.5 & Trisomy 21 & $\begin{array}{c}\text { Vomiting, } \\
\text { hematemesis, } \\
\text { GER }\end{array}$ & $/ /$ & // \\
\hline 3 & 17 & $M$ & 8 & $\begin{array}{c}\text { ASD, trisomy } \\
21\end{array}$ & $\begin{array}{c}\text { Vomiting, } \\
\text { hematemesis, } \\
\text { GER }\end{array}$ & GD and $\mathrm{DB}$ & Erosive gastritis \\
\hline 4 & 72 & $\mathrm{~F}$ & 18 & Trisomy 21 & $\begin{array}{l}\text { Vomiting and } \\
\text { dysphagia }\end{array}$ & $\begin{array}{l}\text { GD and foreign } \\
\text { body }\end{array}$ & - \\
\hline 5 & 70 & $\mathrm{~F}$ & 14 & - & Vomiting & DB and web & $\begin{array}{c}\text { Esophageal } \\
\text { stricture }\end{array}$ \\
\hline 6 & 24 & $\mathrm{~F}$ & 10 & - & $\begin{array}{c}\text { Vomiting, } \\
\text { hematemesis, } \\
\text { GER }\end{array}$ & - & $\begin{array}{c}\text { Erosive gastritis, } \\
\text { web }\end{array}$ \\
\hline 7 & 0.5 & $\mathrm{~F}$ & 2.8 & $\begin{array}{l}\text { Choledochal } \\
\text { cyst }\end{array}$ & Vomiting & DB & - \\
\hline 8 & 0.17 & $M$ & 3 & - & Vomiting & DB & - \\
\hline
\end{tabular}

$M$ - male, F-female, GER - gastroesophageal reflux, ASD - atrial septal defect, GD - gastric dilatation, DB - double bubble.

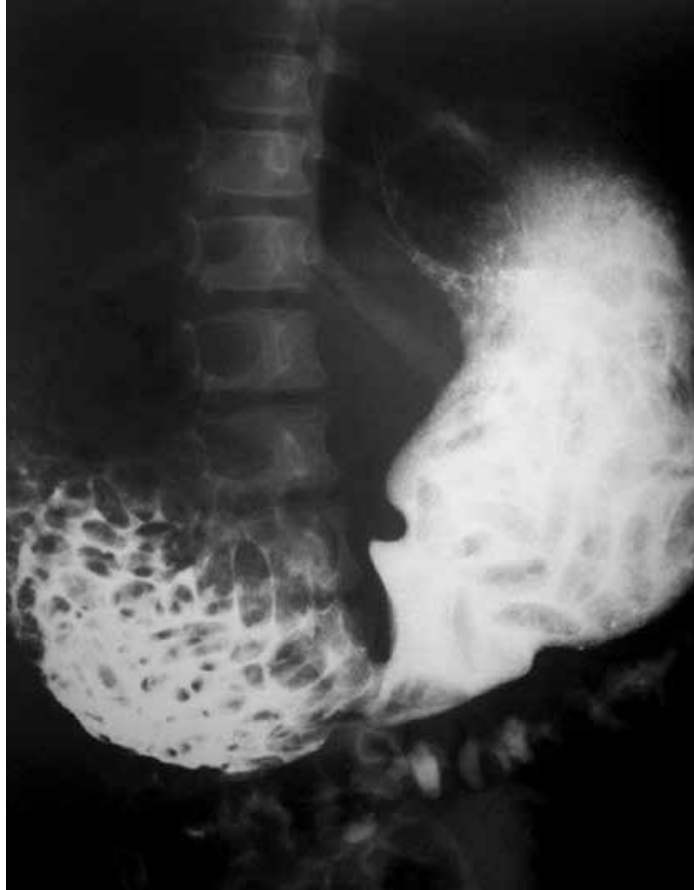

Figure 2. Barium meal shows dilated duodenum proximal to the web and multiple filling defects

The second unusual presentation was dysphagia and FTT (case 5). The patient was a 6-yearold girl who had been managed for esophageal stricture by multiple balloon dilatation and peptic disease medications for many years but relapsed. Eventually, plain abdomen X-ray had shown "double bubble" appearance and barium meal recommended duodenal atresia in "wind sock deformity" type (Figures 4 and 5).

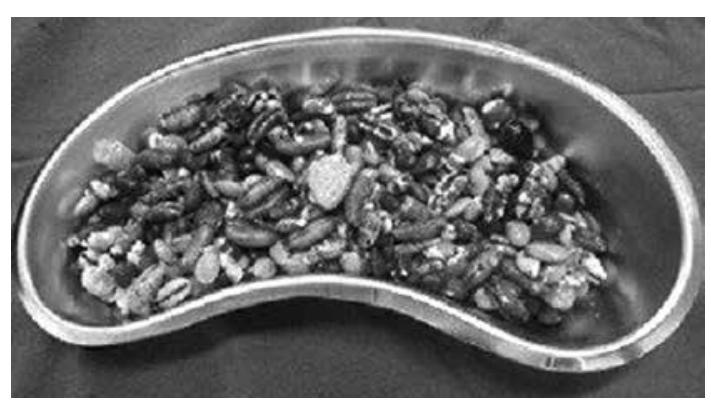

Figure 3. Duodenotomy shows numerous nuts

All stenoses involved the third part of the duodenum, whereby vomiting was non-bilious. Fifty percent of affected patients were associated with trisomy 21, and all of them had severe FTT. In this series, on exploration, the stomach and the duodenum until the third part were grossly dilated. A vertical incision on the first and second portion of the megaduodenum was made. They had a classic duodenal diaphragm arising from the second part of the duodenum (distal to papilla) and had bulged distally. Complete web excision and repair of duodenotomy were done in an anatomical manner. All patients with congenital duodenal obstruction with delayed presentation were cured successfully and without mortality. But the total mortality rate among all patients with congenital intestinal obstruction was $14.8 \%$ (7 duodenal complete atresia, 2 annular pancreas and 3 jeiunal atresia).

\section{Discussion}

Duodenal web was first reported by Boyd in 1845 [11]. It is believed to develop secondarily to a failing in recanalization of the duodenal lu- 


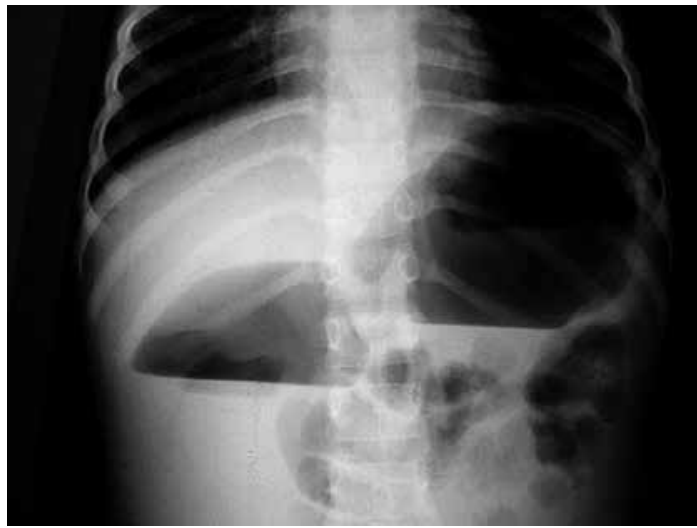

Figure 4. An upright abdominal X-ray showing marked dilatation of duodenum

men between the $8^{\text {th }}$ and $10^{\text {th }}$ weeks of gestation $[3,12]$.

On histology, a web consists of a double layer of epithelium separated by submucosa. Webs are usually located at or near the papilla, and double duodenal webs may occur [12].

More than $50 \%$ of affected patients may be associated with other congenital anomalies, with Down syndrome, annular pancreas, congenital heart disease and malrotation being among the most common associated anomalies. Additionally, polyhydramnios presents in $33 \%$ to $50 \%$ of cases, $45 \%$ of which are premature [1, 3, 5, 8, 9, 13].

In most patients with duodenal atresia, signs and symptoms develop early in the neonatal period. On the other hand, in delayed presentations, there is a duodenum with a fenestrated diaphragm called wind sock deformity. A high index of suspicion is necessary to diagnose these conditions at older ages. In the majority of cases, a deformity of this nature is diagnosed in infants due to obstructive symptoms $[1,2,4,14]$. Postprandial vomiting and food rejection are very common in infants and toddlers. The most common presentation in adults is symptoms of reflux esophagitis and gastric outlet obstruction. However, on rare occasions webs have been associated with pancreatitis [12].

Duodenal web in association with obstruction due to foreign bodies is rare. In the series of Nawaz et al. [15], they presented 22 children with congenital duodenal obstruction. Eight children had duodenal web. Five patients were found to have duodenal diaphragm with a central hole, while the others had complete duodenal diaphragms. Additionally, they reported a case of duodenal obstruction secondary to a duodenal diaphragm with a central hole that was obstructed by date seeds. In contrast to this, Bhat reported a 6-year-old male who presented with an acute duodenal obstruction precipitated by multiple pigmented stones completely blocking the duodenum. In their case, more than 50 small, black stones impacted the small aperture of the web, causing obstruction [14].

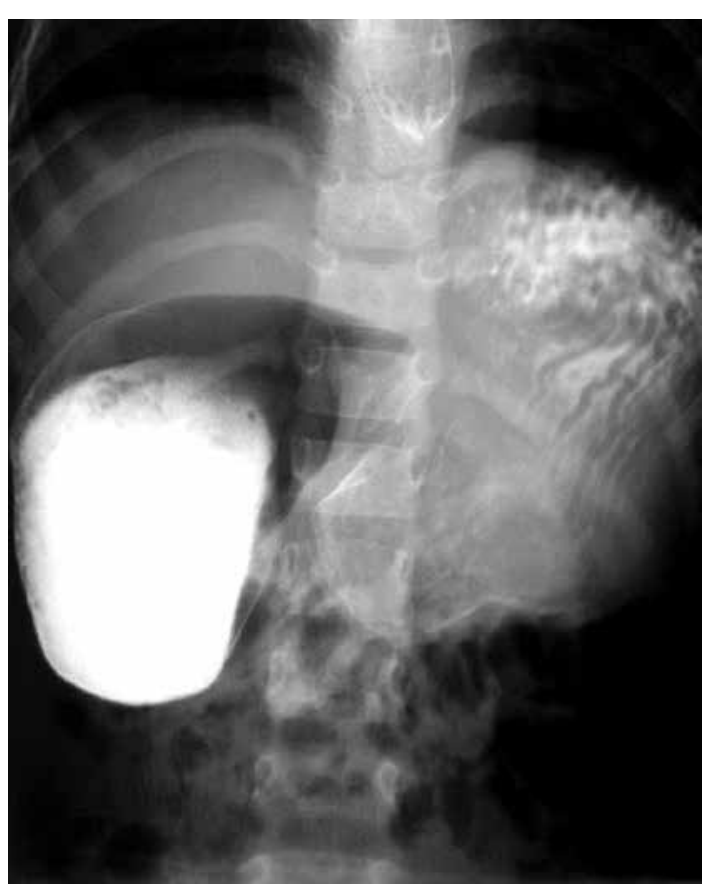

Figure 5. Barium meal showing esophageal stricture, hugely distended duodenum and the mucosal lining of the web

In our series, we have presented some cases with different ages, two of them being unique. Our oldest case was a 6-year-old girl with FTT and an epigastric mass. The presence of 440 seeds as a foreign body that had been tolerated for some years was considered very remarkable. The fact that her chief complaint was food rejection without intestinal obstruction was of key importance. On the other hand, in the next case, the major symptom was dysphagia. We know that this symptom is the end stage of complicated gastroesophageal reflux disease. The key point of this study is notification of two cardinal signs of fenestrated duodenal web: FTT and intractable gastroesophageal reflux disease.

In the majority of cases, diagnosis can be established by plain abdominal radiography. Although the classical "double-bubble" appearance is pathognomonic of duodenal obstruction, symptoms may not be specific in patients with fenestrated duodenal web. In this condition, the barium meal is the ideal procedure of choice for diagnosis $[4,8,14]$. Moreover, in older children flexible endoscopy can reveal the dilatation of the duodenum and the protrusion of the web in the lumen [8]

The basis of treatment is surgical intervention and resection of the diaphragm [4, 5]. In addition, Lee et al. suggested the exploration for a second web at the time of the operation. Furthermore, they showed that a web can be safely resected by endoscopic electrocauterization with an insulated tip, especially in cases with underlying disease such as Down syndrome [8]. 
In conclusion, the fundamental message that needs to be taken from this study is that low frequency of vomiting and atypical abdominal X-ray may contribute to delayed diagnosis of duodenal web with a central hole. Therefore a high index of suspicion is necessary for diagnosis when individuals present beyond the usual age with signs of FTT and intractable gastroesophageal reflux disease.

\section{Acknowledgments}

The authors would like to thank Abbas Aramideh for his cooperation in writing this text.

\section{Conflict of interest}

The authors declare no conflict of interest.

\section{References}

1. Mirza B, ljaz L, Saleem M, Sheikh A. Multiple associated anomalies in a single patient of duodenal atresia: a case report. Cases J 2008; 6: 215.

2. Sarkar S, Apte A, Sarkar N, Sarkar D, Longia S. Vomiting and food refusal causing failure to thrive in a 2 year old: an unusual and late manifestation of congenital duodenal web. BMJ Case Reports 2011; 2011: pii: bcr0120113779.

3. Talabi AO, Sowande OA, Tanimola AG, Adejuyigbe O. Situs inversus in association with duodenal atresia. Afr J Paediatr Surg 2013; 10: 275-8.

4. Jiménez-Moreno MA, Fernández-Crehuet C, FerreiroArgüelles B, Calle-Calle J, Andrade-Bellido R. A rare cause of intestinal obstruction in the adult: duodenal diaphragm. Rev Esp Enferm Dig 2012; 104: 445-6.

5. Escobar MA, Ladd AP, Grosfeld JL, et al. Duodenal atresia and stenosis: long-term follow-up over 30 years. J Pediatr Surg 2004; 39: 867-71.

6. Norman $\mathrm{CH}$, Pacis $\mathrm{AB}$. Congenital duodenal web in an adult. J Natl Med Assoc 1978; 70: 797-8.

7. Aguayo A, Ostlie DJ. Duodenal and intestinal atresia and stenosis. Ashcraft Pediatric Surgery. $6^{\text {th }}$ ed. Saunders, Philadelphia 2014; 414-7.

8. Lee SS, Hwang ST, Jang NG, et al. A case of congenital duodenal web causing duodenal stenosis in a Down syndrome child: endoscopic resection with an insulated-tip knife. Gut Liver 2011; 5: 105-9.

9. van der Zee DC. Laparoscopic repair of duodenal atresia: revisited. World J Surg 2011; 35: 1781-4.

10. Mousavi SA, Sarparast L. lleocecal valve atresia: introduction of a new surgical approach. Afr J Paediatr Surg 2014; 11: 77-8.

11. Boyd R. Description of a malformation of the duodenum, with notices of analogous cases. Med Chir Trans 1845; 28: 329-35.

12. Kollias J, Toouli J. Duodenal web and pancreas divisum causing pancreatitis in an adult. HPB Surg 1994; 7: 231-5.

13. Shankar R, Rao SP, Shetty KB. Duodenal atresia in association with situs inversus abdominus. J Indian Assoc Pediatr Surg 2012; 17: 71-2.

14. Bhat NA. Congenital duodenal diaphragm and enteroliths: a unique complication. J Indian Assoc Pediatr Surg 2009; 14: 226-7.

15. Nawaz A, Matta H, Jacobsz A, Trad O, Al Salem AH. Congenital duodenal diaphragm in eight children. Ann Saudi Med 2004; 24: 193-7. 